\title{
Effectiveness of Entonox use in pain and comfort level of parturient mothers during first stage of labor
}

James $\mathrm{S}^{*}$

\section{*Corresponding author:}

Ms. Sruthi James, MSN, Research Coordinator, Trauma Surgery, Hamad general Hospital, Doha, Qatar.

Email: shruthijames@gmail.com $\underline{\text { ORCID }}$

\section{Information about the article:}

Received: February 17, 2019

Accepted: February 20, 2019

Published online: Dec 27, 2019

Publisher

Nepal Health Research Society, Bahundhara -6, Gokarnesowor Municipality, Kathmandu, Nepal

eISSN 2382-5545, ISSN 2676-1343 (Print)

(C) The Author(s). 2019

Content licensing: CC BY 4.0

\section{ABSTRACT}

\section{Background}

Natural childbirth is a beautiful experience with many safe options and benefits. Labor pain is widely viewed as being nothing more than the perception of unpleasant sensation. Many methods have been used for pain relief which constitutes non-pharmacological methods such as relaxation therapy and others are by pharmacological agents. Entonox, homogenous gas mixture of 50:50 nitrous oxide and oxygen, a form of inhalation analgesia is very effective in reducing pain and thereby progressing to painless vaginal delivery. The usage of Entonox is known worldwide, however its usage in Kerala is comparably very less. The objective of the study was to assess the effectiveness of inhalation analgesia (Entonox) in pain and comfort during first stage of labor among parturient mothers.

\section{Materials and methods}

A quasi-experimental pretest - posttest control group with 60 mothers (30 each in experimental and control) was the adopted design with parturient mothers in 37-40 weeks of gestation from selected hospitals in Kollam, Kerala. Demographic proforma, visual analogue scale and comfort assessment checklist were the tools used. The statistically significant relationships were identified by descriptive and inferential statistics. Ethical clearance was granted by the committee in Kollam, Kerala.

\section{Results}

Out of $60,45 \%$ of the mothers were in the age group of 2429 years, $35 \%$ had undergone upper primary education, $61.7 \%$ were primi gravidae and $55 \%$ of them were in the gestational age of $39-40$ weeks. The mean post interventional pain score of the experimental group was lower than that of control group (4.07/9.93, $\mathrm{p}<0.05)$. Also, the mean post interventional comfort score of the experimental group was lower than that of control group (7.37/15.77, $\mathrm{p}<0.05)$.

\section{Conclusion}

Entonox provides significant pain relief and improves comfort and it can be quickly implemented during painful labor. By further exploration and research studies would help the mothers be free to choose the harmless Entonox during labor.

\section{Keywords}

Entonox, labor Kerala, pain 